\title{
Highlights of IUGA 36th Annual Meeting in Lisbon 2011
}

\author{
Joseph K-S Lee • Anna Rosamilia
}

Received: 2 August 2011 /Accepted: 10 August 2011 / Published online: 3 September 2011

(C) The International Urogynecological Association 2011

\section{Introduction}

Dissemination, healthy debate, and cross-fertilization of ideas is crucial to scientific progress. The 36th IUGA Annual Meeting, which was held in Lisbon, Portugal from 28th Jun to 2nd Jul 2011, provided a superb platform for an academic program rich in depth and scope, within the field of female pelvic floor medicine and reconstructive surgery.

The scientific program consisted of 7 podium sessions, 10 oral poster sessions, 2 video session (1 with data), 2 state-of-the-art lectures, 3 interactive discussions/round table, and 32 workshops together with the EUGA Surgical Course and Ibero-American Urogynecology Session. A total of 1,800 delegates attended, which included 205 fellows, 48 physiotherapist, and 28 nurses and represented an increase of $17 \%$ in attendance compared to the year 2009. The total number of submitted abstracts has also increased steadily from 457 (Cancun, 2007), 528 (Taipei, 2008), 571 (Lake Como, 2009) to 527 this year. Thirty-five percent of those submitted gained a presentation.

As was the case in every IUGA meeting, the workshops were extremely popular with all but three sold out. They are the most effective educational tool, and the topics included basic science, pelvic floor rehabilitation, anatomy, clinical

\footnotetext{
J. K.-S. Lee $(\bowtie)$

Department of Urogynaecology, Mercy Hospital for Women, 169 Studley Road,

Heidelberg, VIC 3084, Australia

e-mail: joseph.lee@southernhealth.org.au
}

J. K.-S. Lee · A. Rosamilia

Pelvic Floor Clinic, Monash Medical Centre,

Moorabbin, VIC, Australia assessment, imaging, specific stress incontinence and prolapse surgical techniques, fistula, pelvic pain, obstetric injury, and colorectal management. A number were handson and the fellows' workshop for the first time included live animal surgery.

The opening podium session on Stress Urinary Incontinence (SUI) included the Axel Ingelmann-Sundberg Award for Best Abstract awarded to Matt Barber [1]. This was a blinded multicenter randomized controlled trial (RCT) comparing tension-free vaginal tape (TVT) vs TVT-secur using a definition of cure as an Incontinence Severity Index (ISI) score of 0 and no retreatment for SUI [1]. The results showed no difference in cure rate $(60 \%$ vs $57 \%$, respectively), but the TVT-secur group had a higher ISI score (2.2/ 2.7 vs $1.5 / 1.9 ; p=0.15$ ) with a higher proportion of those having ISI $=8(16 \%$ vs $5 \%$; $p=0.026)$. The best oral poster by a fellow was also in the Stress Urinary Incontinence category and was awarded to A. Smith [2] who reported a RCT showing no difference at 6 months follow-up of Monarc vs Miniarc sling.

The podium session on Pregnancy/Epidemiology included the award winner, K. Elenskaia [3] for the best podium presented by a fellow. This was a longitudinal study of 182 nulliparous women which showed a change in Pelvic Organ Prolapse Quantitation in the vaginal delivery compared with cesarean delivery group but no difference in symptoms or quality of life (Personal Assessment Questionnaire-Pelvic Floor) at 5 years follow-up. The Assessment \& Urodynamic podium and oral poster sessions included a number of important studies particularly expanding on the role of ultrasound and other imaging in addition to urodynamic assessment.

There were 12 videos shown and the award for Best Video (with data) was presented to C. Schmid [4] who presented a case series (20) of surgery following prior mesh 
repair (12 anterior, 9 posterior, 3 total mesh, and 2 sacral colpopexies). Subsequent surgery included laparoscopic sacral colpopexy in $60 \%$ with a clear video demonstration of the principles of this procedure illustrating the specific approach when dealing with mesh kit failure.

The podium and oral poster session on Pelvic Organ Prolapse included follow-up of large case series of specific procedures including native tissue repair and mesh kits. A special presentation on the process by which the new sexual function questionnaire is being validated preceded the podium sessions on Sexual Function, Quality of Life, Colorectal, and Voiding Dysfunction categories.

The Basic Science and Overactive Bladder (OAB) oral poster session was on the morning after the spectacular gala dinner, always a challenging time slot. It included some insights into potential treatments with stem cells in addition to a neuromodulation patch, botulinum A toxin Cochrane review, and intracellular bacterial colonization of urothelial cells as a possible etiology for OAB.

The State-of-the-Art Lecture: Urogynecology Through Time - a Modern Perspective on Surgical History was delivered by Dr. Amelia Ricon-Ferraz and featured an extensive image library of historical procedures and instruments. The Ulf Ulmsten Memorial Lecture: the Pelvic Floor: Fallacies, Fascias and Facts was given by Professor John DeLancey. This elegant lecture focused on understanding the cause (or differentiating it from the effects) of prolapse with a unifying theory of muscle and connective tissue damage and midline, apical, and paravaginal defects.

The Roundtable: Biomechanical Behavior of the Pelvic Floor included contributions from James Ashton-Miller, Teresa Mascarenhas, and Michel Cosson. There were fascinating insights into the prediction of the most efficient type of maternal pushing in vaginal childbirth and the use of finite element analysis to produce predictive modeling to identify areas of high strain.

The second Roundtable was Prolapse Surgery: Debating Your Approach with contributions from Brigitte Fatton, Marie Fidela Paraiso, and Karl Tamussino which included enthusiastic audience participation. This was also the case with the second interactive session, the inaugural Stump the Professor where fellows presented clinical case histories of difficult complexity to challenge the acumen of eminent professors (and also IUGA past presidents).

\section{Conclusions}

We highlighted some of the best presentations and wish to apologize in advance for any omissions. Each award winning abstract is referenced to the conference supplement of the International Urogynecology Journal, where we encourage interested readers to further explore, or visit the IUGA website at http://www.iuga.org. It has been more than a century since George White's [5] comment on the optimal management of cystocele, with a plethora of surgical procedures described since, most recently being the use of mesh kits. On this note, we leave our readers with Professor DeLancey's poem-Ode to a Cystocele:

Poor cystocele, you're sitting there

Between the bladder and the air

Bulging out from where you hide

Ashamed they'll see your wounded pride.

Misunderstood, neglected too,

You've cringed when science leered at you.

Passed-by along the road to fame

Your destiny seemed filled with shame.

But now you're modeled—spun around

Displayed in 3D shows with sound;

On video you're gaining fame

Soon all will think you're not the same.

So cystocele please don't despair

Your unjust burden bravely bear

For though your cause is still conjecture

At least you have this famous lecture

Ode to a Cystocele, By John O. L. DeLancey, MD

On the occasion of the Ulf Ulmsten Lecture, "Pelvic Organ Prolapse: Fallacies, Fascias, and Facts," presented at the International Urogynecology Society Meeting Lisbon, Portugal, July 1, 2011. Inspired by Ode to the Urethra [6].

Acknowledgments We wish to acknowledge the tremendous work and contribution from Prof. Teresa Mascarenhas, together with members of the Scientific Committee led by Dr. Michele Meschia. We also acknowledge the contributions from other IUGA committees and the executive to make Lisbon a very memorable IUGA meeting.

Conflicts of interest JL \& AR are investigators in an ongoing RCT of mid-urethral slings and have received an external research grant from American Medical Systems.

\section{References}

1. Barber MD (2011) A blinded multi-center randomized trial comparing TVT-secur "U" to the tension-free vaginal tape (TVT) for the surgical treatment of stress urinary incontinence. Int Urogynecol J Pelvic Floor Dysfunct 22(Suppl 1):S2-S3

2. Smith AL, Karp CD, Gross G, Davilla G, Aguilar VC (2011) Transobturator versus single incision slings in women with stress urinary incontinence: a prospective randomized controlled trial. Int Urogynecol J Pelvic Floor Dysfunct 22(Suppl 1):S54S55 
3. Elenskaia K, Thakar R, Sultan AH, Scheer I, Srivastava R, Onwude JL (2011) Does mode of delivery affect pelvic organ support and quality of life? Int Urogynecol J Pelvic Floor Dysfunct 22(Suppl 1):S9-S10

4. Schmid C, O'Rouke P, Maher C (2011) Surgical management of recurrent pelvic organ prolapse after mesh prolapse surgery. Int Urogynecol J Pelvic Floor Dysfunct 22(Suppl 1):S49-S50
5. White G (1909) Cystocele, a radical cure by suturing lateral sulci of vagina to white line of pelvic fascia. JAMA 21:17071710

6. Westerhout FC Jr (1982) In: Slate WB (ed) Disorders of the female urethra and urinary incontinence, 2nd edn. Williams and Wilkins Co, Baltimore 